\title{
Fabrication of Mixed-Charge Polypeptide Coating for Enhanced Hemocompatibility and Anti-Infective Effect
}

Qiang Gao, Xu Li, Weijiang Yu, Fan Jia, Tiantian Yao, Qiao Jin, and Jian Ji*

MOE Key Laboratory of Macromolecule Synthesis and Functionlization, Department of Polymer

Science and Engineering, Zhejiang University, Hangzhou 310027, China

Supporting Information 


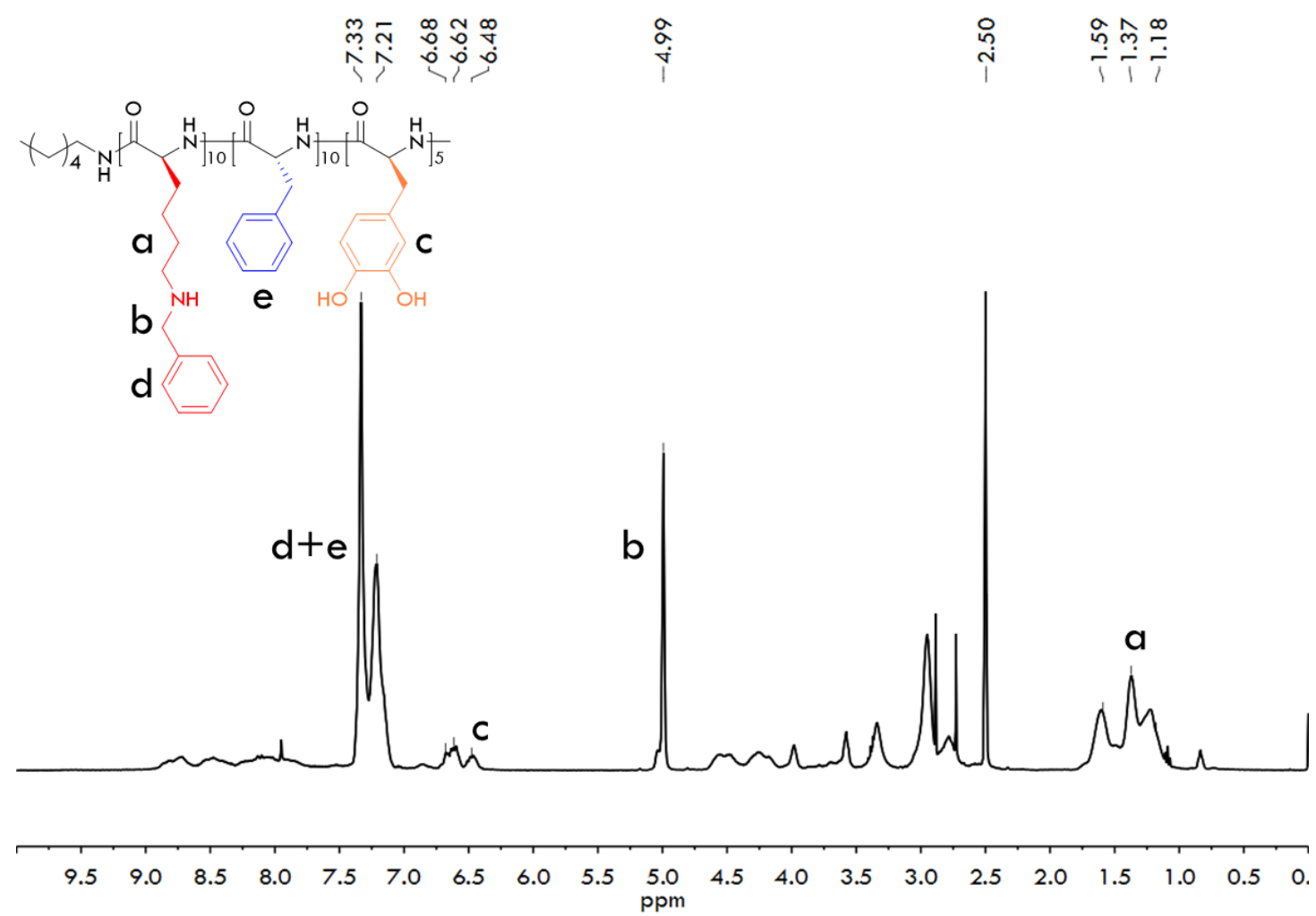

Fig. S1. ${ }^{1} \mathrm{H}-\mathrm{NMR}$ spectra of $\mathrm{cPep}(\mathrm{z})$ in DMSO- $d_{6}$. Peaks at 2.5 (DMSO) correspond to the residual solvents. 


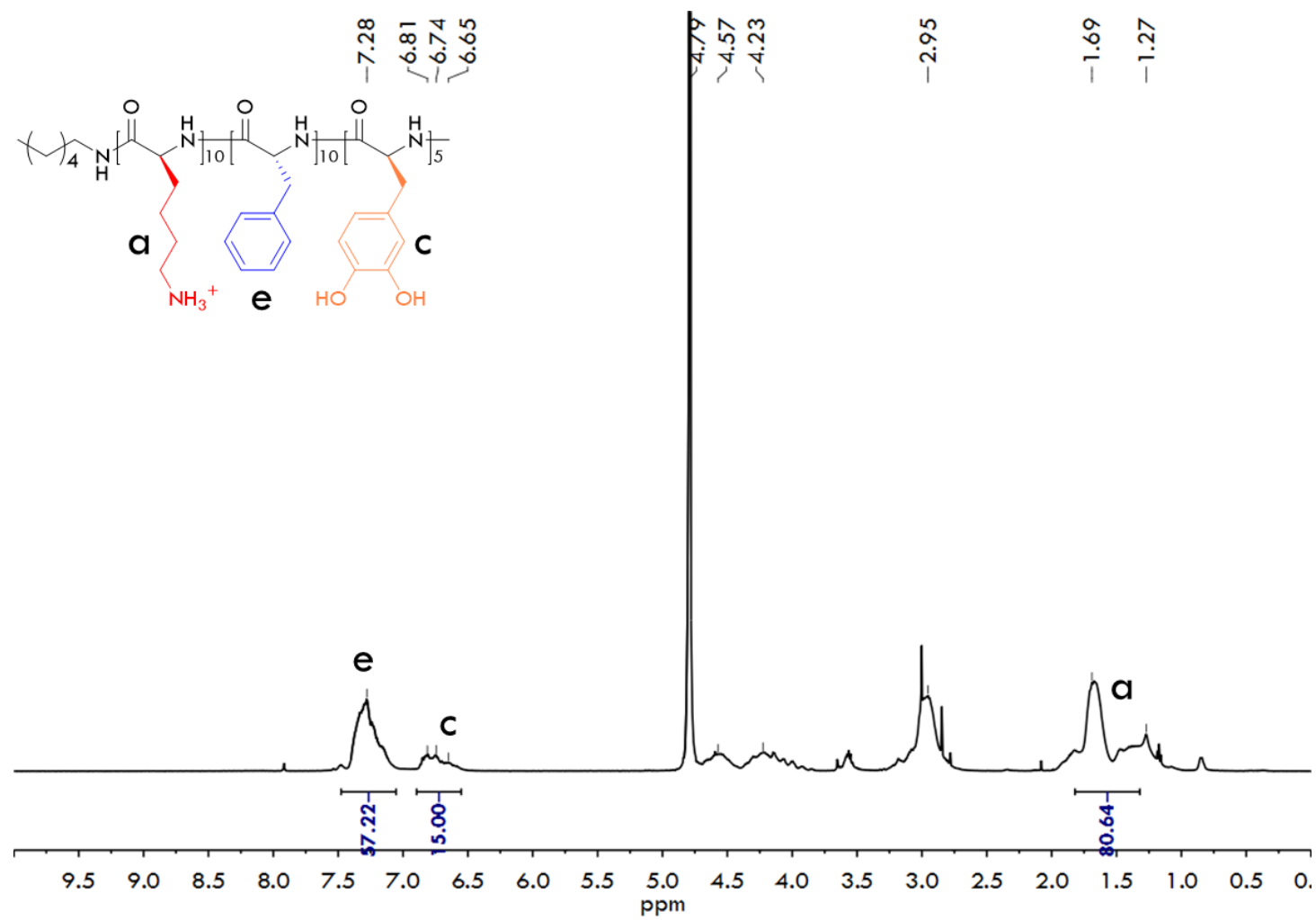

Fig. S2. ${ }^{1} \mathrm{H}-\mathrm{NMR}$ spectra of cPep in $\mathrm{D}_{2} \mathrm{O}$. Peaks at $4.79\left(\mathrm{D}_{2} \mathrm{O}\right)$ correspond to the residual solvents. 


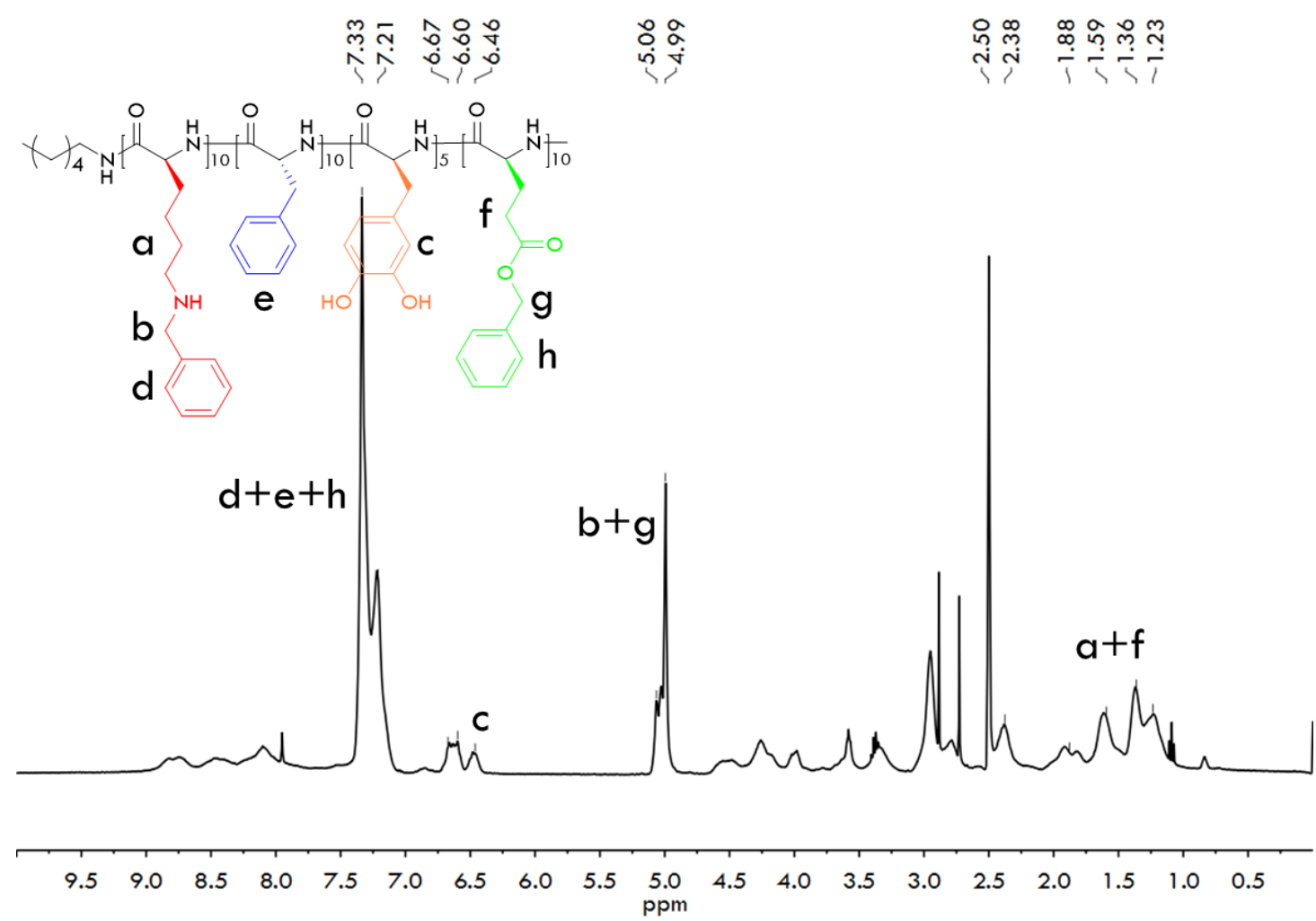

Fig. S3. ${ }^{1} \mathrm{H}-\mathrm{NMR}$ spectra of mPep(z) in DMSO- $d_{6}$. Peaks at 2.5 (DMSO) correspond to the residual solvents. 


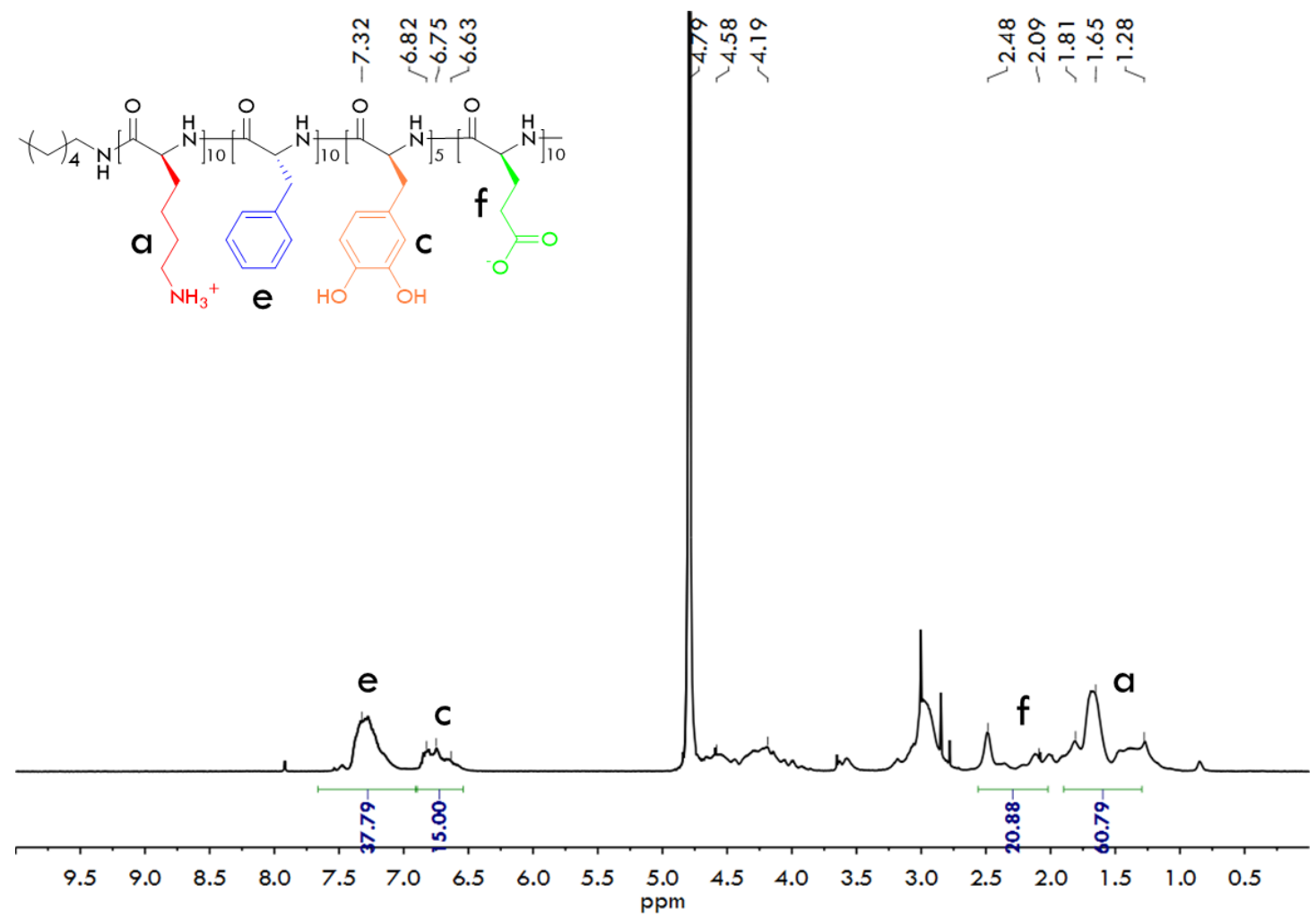

Fig. S4. ${ }^{1} \mathrm{H}-\mathrm{NMR}$ spectra of mPep in $\mathrm{D}_{2} \mathrm{O}$. Peaks at $4.79\left(\mathrm{D}_{2} \mathrm{O}\right)$ correspond to the residual solvents. 